\title{
FORECASTING HARGA SAHAM MENGGUNAKAN METODE SIMPLE MOVING AVERAGE DAN WEB SCRAPPING
}

\author{
Dessy Tri Anggraeni \\ Dosen Universitas Gunadarma \\ Jalan Margonda No 100, Depok \\ Sur-el : dessytri@staff.gunadarma.ac.id
}

\begin{abstract}
The fluctuative of stock prices in a secondary market provide the possibility for investors/traders to gain profits through the difference in stock prices (capital gain). In order to obtain these benefits, it is necessary to analyze before buying shares, through fundamental and technical analysis. One of several methods in Technical Analysis is Simple Moving Average Method. This method can be used to predict (forecast) stock prices by calculating moving average of the stock price history. Historical stock prices can be obtained in real time using the Web Scrapper technique, so the results is more quickly and accurately. Using the MAPE (Mean Absolute Percent Error) method, the level of accuracy of forecasting can be calculated. As a result, the program was able to run successfully and was able to display the value of forecasting and the level of accuracy for the entire data tested in LQ45. Besides forecasting with a value of $N$ $=5$ has the highest level of accuracy that reaches 97,6\% while the lowest one is using the value of $N=30$ which is $95,0 \%$.
\end{abstract}

Keywords: Stock, Forecsting, Simple Moving Average, Web Scrapping, MAPE

\begin{abstract}
Abstrak : Harga saham di pasar sekunder yang fluktuatif memberikan kemungkinan kepada investor/trader untuk memperoleh keuntungan melalui selisih harga saham (capital gain). Agar memperoleh keuntungan tersebut perlu dilakukan analisa sebelum membeli saham, baik analisa fundamental maupun teknikal. Salah satu metode dalam Analisa Teknikal adalah Metode Simple Moving Average. Metode ini dapat digunakan untuk memprediksi (forecasting) harga saham di dengan memperhitungkan riwayat harga saham. Riwayat harga saham bisa diperoleh secara real time dengan menggunakan teknik Web Scrapper, sehingga hasil bisa didapat lebih cepat dan akurat. Menggunakan metode MAPE (Mean Absolute Percent Error) bisa dihitung tingkat akurasi forecasting. Hasilnya, program berhasil berjalan dan mampu menampilkan nilai forecasting serta tingkat akurasi untuk keseluruhan data yang diujikan yaitu semua saham di LQ45. Selain itu forecasting dengan nilai $N=5$ memiliki tingkat akurasi paling tinggi yaitu mencapai 97,6 \% sedangkan yang paling rendah adalah menggunakan nilai $N=30$ yaitu 95,0\%.
\end{abstract}

Kata kunci: Saham, Forecsting, Simple Moving Average, Web Scrapping, MAPE

\section{PENDAHULUAN}

Saham menurut Kamus Besar Bahasa Indonesia (KBBI) adalah surat bukti pemilikan bagian modal perseroan terbatas yang memberi hak atas dividen dan lain-lain menurut besar kecilnya modal yang disetor [1]. Sedangkan menurut Bursa Efek Indonesia, saham didefinisikan sebagai tanda penyertaan modal seseorang atau pihak (badan usaha) dalam suatu perusahaan atau perseroan terbatas, maka pihak tersebut memiliki klaim atas pendapatan perusahaan, klaim atas asset perusahaan, dan berhak hadir dalam Rapat Umum Pemegang Saham (RUPS) [2].

Saham dapat diperjualbelikan melalui pasar primer dan pasar sekunder. Pasar primer merupakan pasar dimana terjadi penjualan untuk 
pertama kalinya kepada publik atau terjadi saat IPO (Initial Public Offering). Sedangkan pasar sekunder terjadi setelah IPO, sehingga transaksi sudah tidak melibatkan perusahaan lagi secara langsung, akan tetapi terjadi jual beli antar investor saja. Harga saham di pasar sekunder bersifat fluktuatif. Fluktuasi harga ini memberi peluang kepada investor untuk mendapatkan keuntungan melalui selisih harga beli dan harga jual (capital gain). Akan tetapi juga memiliki potensi kerugian apabila harga jual kurang dari harga beli (capital loss).

Investor atau trader harus tahu kapan dan di harga berapa harus membeli maupun menjual saham supaya lebih banyak memperoleh keuntungan dan terhindar dari kerugian. Investor biasanya menggunakan dua metode yaitu Analisis Fundamental dan Analisis Teknikal. Analisis fundamental adalah analisis harga saham yang menitikberatkan pada kinerja perusahaan dan analisis ekonomi yang akan mempengaruhi masa depan perusahaan [3].

Sedangkan Analisis Teknikal adalah metode untuk memprediksi harga saham dan tren pasar di masa depan dengan mempelajari grafik dan aksi pasar di masa lalu [4]. Dasar pemikiran yang dipakai dalam analisis teknikal adalah [5]:

a) Market price discounts everything

Setiap peristiwa dapat berpengaruh terhadap pergerakan harga saham dan peristiwa tersebut akan tercermin dalam harga seketika itu juga.

b) Price moves in trend

Harga bergerak dalam tren, sehingga dengan mempelajari tren saham, kita bisa menentukan langkah apa yang akan diambil. c) History repeats itself

Data historis dapat digunakan untuk memprediksi harga saham, karena adanya faktor psikologis para pelaku pasar yang bersifat konstan dan dapat berulang kembali.

Pada penelitian ini, penulis menggunakan analisis teknikal karena lebih mudah diimplementasikan, dimana hanya membutuhkan data historis harga saham saja. Moving Average adalah salah satu bagian dari metode peramalan time series [6]. Metode Moving Average memiliki dua varian yaitu Simple Moving Average dan Weighted/Exponential Moving Average. Perbedaan keduanya adalah pada teknik pembobotan. Pada Weighted Moving Average, bobot yang lebih tinggi diberikan pada periode yang semakin dekat dengan periode yang diramalkan [7].

Penelitian ini akan membahas bagaimana membuat aplikasi forecasting (peramalan) harga saham dengan menggunakan metode Simple Moving Average (rata-rata bergerak). Adapun untuk mendapatkan data harga saham akan digunakan metode Web Scrapping yaitu mengambil data langsung dari situs penyedia data.

\section{METODOLOGI PENELITIAN}

\subsection{Objek Penelitian}

Objek penelitian yang digunakan dalam adalah saham-saham yang tergabung dalam LQ45, yang dapat dilihat pada tabel 1 . 
Tabel 1. Saham-Saham LQ45

\begin{tabular}{|c|c|c|}
\hline No & Kode & Nama Perusahaan \\
\hline 1 & ADHI & Adhi Karya (Persero) Tbk. \\
\hline 2 & ADRO & Adaro Energy Tbk \\
\hline 3 & AKRA & AKR Corporindo Tbk. \\
\hline 4 & ANTM & Aneka Tambang Tbk. \\
\hline 5 & ASII & Astra International Tbk. \\
\hline 6 & ASRI & Alam Sutera Reality Tbk. \\
\hline 7 & $\mathrm{BBCA}$ & Bank Central Asia Tbk. \\
\hline 8 & BBNI & Bank Negara Indonesia (Persero) Tbk. \\
\hline 9 & BBRI & Bank Rakyat Indonesia (Persero) Tbk. \\
\hline 10 & BBTN & $\begin{array}{l}\text { Bank Tabungan Indonesia (Persero) } \\
\text { Tbk. }\end{array}$ \\
\hline 11 & BKSL & Sentul City Tbk \\
\hline 12 & BMRI & Bank Mandiri (Persero) Tbk. \\
\hline 13 & BSDE & Bumi Serpong Damai Tbk. \\
\hline 14 & CPIN & Charoen Pokphand Indonesia Tbk. \\
\hline 15 & ELSA & Elnusa Tbk. \\
\hline 16 & EXCL & XL Axiata Tbk. \\
\hline 17 & GGRM & Gudang Garam Tbk. \\
\hline 18 & HMSP & HM Sampoerna Tbk. \\
\hline 19 & ICBP & Indofood CBP Sukses Makmur Tbk. \\
\hline 20 & INCO & Vale Indonesia Tbk. \\
\hline 21 & INDF & Indofood Sukses Makmur Tbk. \\
\hline 22 & INDY & Indika Energy Tbk. \\
\hline 23 & INKP & Indah Kiat Pulp \& Paper \\
\hline 24 & INTP & Indocement Tunggal Prakasa Tbk. \\
\hline 25 & ITMG & Indo Tambangraya Megah Tbk \\
\hline 26 & JSMR & Jasa Marga (Persero) Tbk. \\
\hline 27 & KLBF & Kalbe Farma Tbk. \\
\hline 28 & LPKR & Lippo Karawaci Tbk. \\
\hline 29 & LPPF & Matahari Department Store Tbk. \\
\hline 30 & MEDC & Medco Energi Internasional Tbk \\
\hline 31 & $\mathrm{MNCN}$ & Media Nusantara Citra Tbk. \\
\hline 32 & PGAS & Perusahaan Gas Negara (Persero) Tbk. \\
\hline 33 & PTBA & $\begin{array}{l}\text { Tambang Batubara Bukit Asam } \\
\text { (Persero) Tbk. }\end{array}$ \\
\hline 34 & РТPP & PP (Persero) Tbk. \\
\hline 35 & SCMA & Surya Citra Media Tbk. \\
\hline 36 & SMGR & Semen Indonesia (Persero) Tbk. \\
\hline 37 & SRIL & Sri Rejeki Isman Tbk. \\
\hline 38 & SSMS & Sawit Sumbermas Sarana Tbk. \\
\hline 39 & TLKM & $\begin{array}{l}\text { Telekomunikasi Indonesia (Persero) } \\
\text { Tbk. }\end{array}$ \\
\hline 40 & TPIA & Chandra Asri Petrochemical Tbk. \\
\hline 41 & UNTR & United Tractors Tbk. \\
\hline 42 & UNVR & Unilever Indonesia Tbk. \\
\hline 43 & WIKA & Wijaya Karya (Persero) Tbk. \\
\hline 44 & WSBP & Waskita Beton Precast Tbk. \\
\hline 45 & WSKT & Waskita Karya (Persero) Tbk. \\
\hline
\end{tabular}

Berdasarkan yang sudah dijelaskan sebelumnya pada bagian pendahuluan, metode peramalan harga saham yang digunakan pada penelitian ini adalah menghitung simple moving average (rata - rata bergerak) dan akurasi forecasting, serta menggunakan metode web scrapping dalam pengambilan datanya.

\subsection{Metode Forecasting Simple Moving Average (SMA)}

Simple Moving Average adalah salah satu metode peramalan dengan cara menghitung ratarata dengan rentang waktu tertentu ke belakang dengan tidak melakukan pembobotan. Metode ini baik digunakan untuk data yang bersifat tidak stabil, tidak memiliki tren, dan tidak menggunakan pembobotan [7].

Rumus untuk menghitung nilai Simple Moving Average adalah sebagai berikut :

$$
\text { Rata }- \text { rata Bergerak }=\frac{\text { Permintaan data Periode Sebelumnya }}{n}
$$

Nilai $\boldsymbol{n}$ bisa bervariasi tergantung keinginan user. Nilai $\boldsymbol{n}$ yang berbeda akan membuat keakuratan data berbeda pula.

\subsection{Menghitung Akurasi Forecasting}

Terdapat beberapa metode penghitungan akurasi forecasting, seperti Mean Forecast Error (MFE), Mean Absolute Deviation (MAD), Mean Squre Error (MSE), dan Mean Absolute Percent Error (MAPE). Pada penelitian ini akan digunakan Mean Absolute Percent Error (MAPE) sebagai metode penghitungan akurasi. Hal ini dikarenakan metode ini dinilai lebih akurat dan lebih mudah dipahami dibandingkan dengan metode-metode yang lainnya [8].

Rumus penghitungan MAPE adalah sebagai berikut :

$$
\left(\frac{1}{n} \sum \frac{\mid \text { actual-forecast } \mid}{\mid \text { Actual } \mid}\right) * 100
$$


dimana,

$n$ : jumlah data/record

Actual : nilai aktual

Forecast : nilai perkiraan/forecasting

Hasil perhitungan adalah berupa persen, sehingga semakin kecil persentase error, maka semakin akurat peramalan yang dilakukan.

Tingkat akurasi bisa dihitung dengan rumus:

$$
\text { Tingkat Akurasi }=100 \%-M A P E \ldots \ldots(3)
$$

\subsection{Web Scrapping}

Web Scrapping adalah proses pengambilan dokumen semi terstruktur dari internet, umumnya berupa halaman-halaman web dalam bahasa markup seperti HTML atau XHTML, dan menganalisa dokumen tersebut untuk diambil data tertentu dari halaman tersebut untuk dipergunakan kembali dalam bidang lain.

Langkah-langkah untuk menggunakan Web Scrapping secara umum adalah sebagai berikut [9][10]:

\section{Create Scrapping Template}

Mempelajari dokumen HTML dari situs yang akan diambil informasinya

\section{Explore Site Navigation}

Mempelajari teknik navigasi pada situs yang akan diambil informasinya untuk ditanamkan pada aplikasi Web Scrapper.

\section{Automate Navigation an Extraction}

Mengotomatisasi pengambilan informasi dari situs berdasarkan analisa pada langkah 1 dan 2 .

\section{Extracted Data and Package History}

Mendapatkan hasil yang diinginkan dan menyimpannya pada database lokal untuk kemudian diolah sesuai keinginan.
Data harga saham diambil dari situs resmi Yahoo Finance di alamat : https://finance.yahoo.com/. Gambar 1 di bawah ini adalah contoh screenshoot data saham ADRO yang diambil dari situs Yahoo Finance.

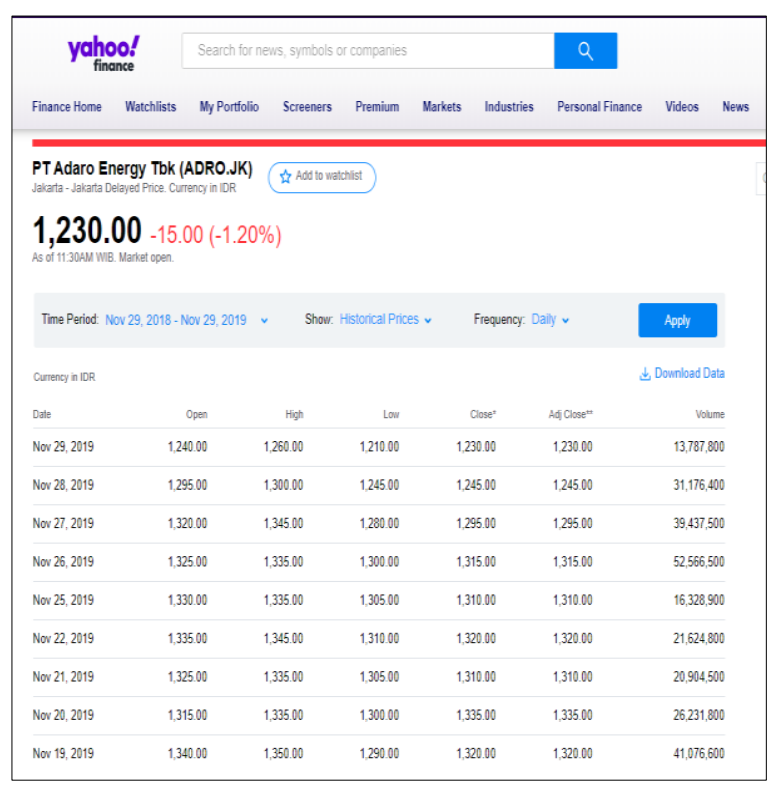

Gambar 1. Contoh Screenshoot Situs Yahoo Finance

\subsection{Perancangan Program}

Perancangan program dengan menggunakan flowchart dapat dilihat pada gambar 2 dengan penjelasan sebagai berikut :

a) Program akan meminta user untuk memasukkan kode saham perusahaan yang ingin di-forecast harga sahamnya sesuai dengan kode saham di Bursa Efek.

b) Selanjutnya program akan mengakses situs penyedia informasi harga saham, yaitu https://finance.yahoo.com/ melalui program Python.

c) Program akan mengunduh halaman situs yang dimaksud dan melakukan Web Scrapping.

d) Dari proses (c), akan didapatkan harga saham harian perusahaan yang dimaksud, yaitu data 
tanggal dan penutupan saham. Data tersebut kemudian disimpan ke dalam Array.

e) Melakukan perhitungan forecasting dengan menggunakan metode Simple Moving Average dari data Array yang sudah didapat sebelumnya.

f) Melakukan perhitungan keakurasian forecasting menggunakan Metode MAPE.

g) Menampilkan hasil forecasting dan tingkat akurasi forecasting.

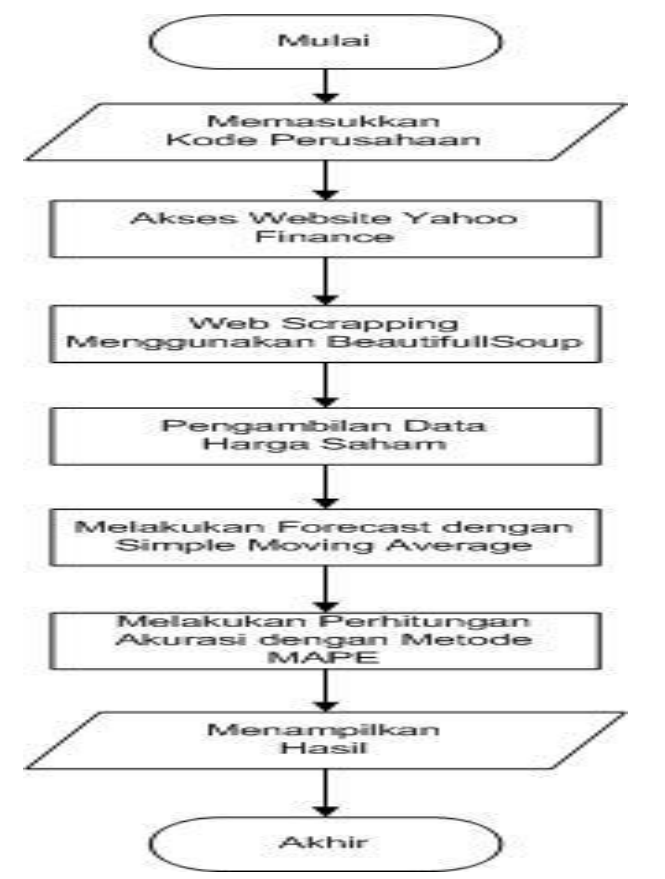

Gambar 2. Flowchart Program

Forecasting Harga Saham

\section{HASIL DAN PEMBAHASAN}

Pada penelitian ini, pembahasan akan dibagi ke dalam empat sub-bahasan, yaitu : Pembuatan Program, Uji Coba Program, serta Analisa Keakuratan Hasil Forecasting.

\subsection{Pembuatan Program}

Program yang akan dibuat adalah program sederhana berbasis text. Program dibuat dengan menggunakan bahasa pemrograman Python dan libary BeautifullSoup. BeautifullSoup adalah library yang khusus digunakan untuk melakukan web scrapping pada Python.

Beberapa penggalan kode program adalah sebagai berikut :

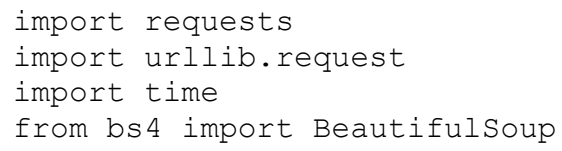

Kode program ini menunjukkan bahwa program akan menggunakan library requests, urllib, time, dan BeautifullSoup.

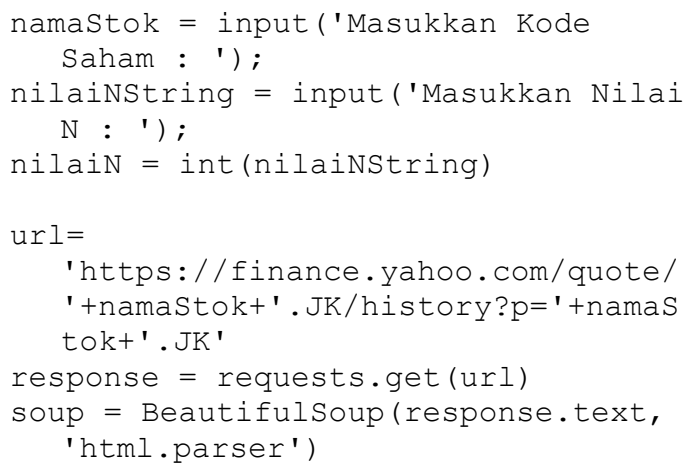

Kode program di atas adalah script untuk mengambil data dari situs Yahoo Finance sesuai dengan kode saham yang diinputkan.

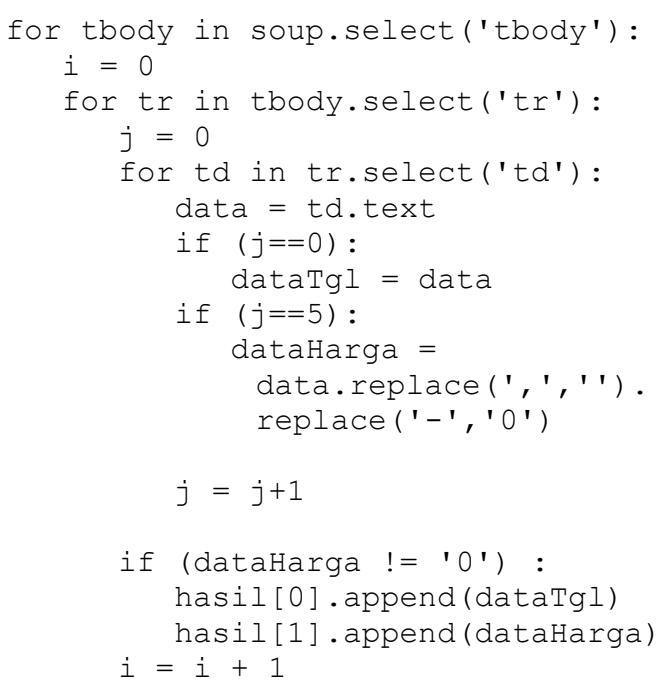

Selanjutnya program akan melakukan web scrapping dan hanya mengambil data yang diperlukan yaitu data tanggal dan harga 
penutupan saham. Kedua data ini kemudian dimasukkan ke dalam variabel Array untuk selanjutnya dilakukan perhitungan forecasting dan tingkat akurasi.

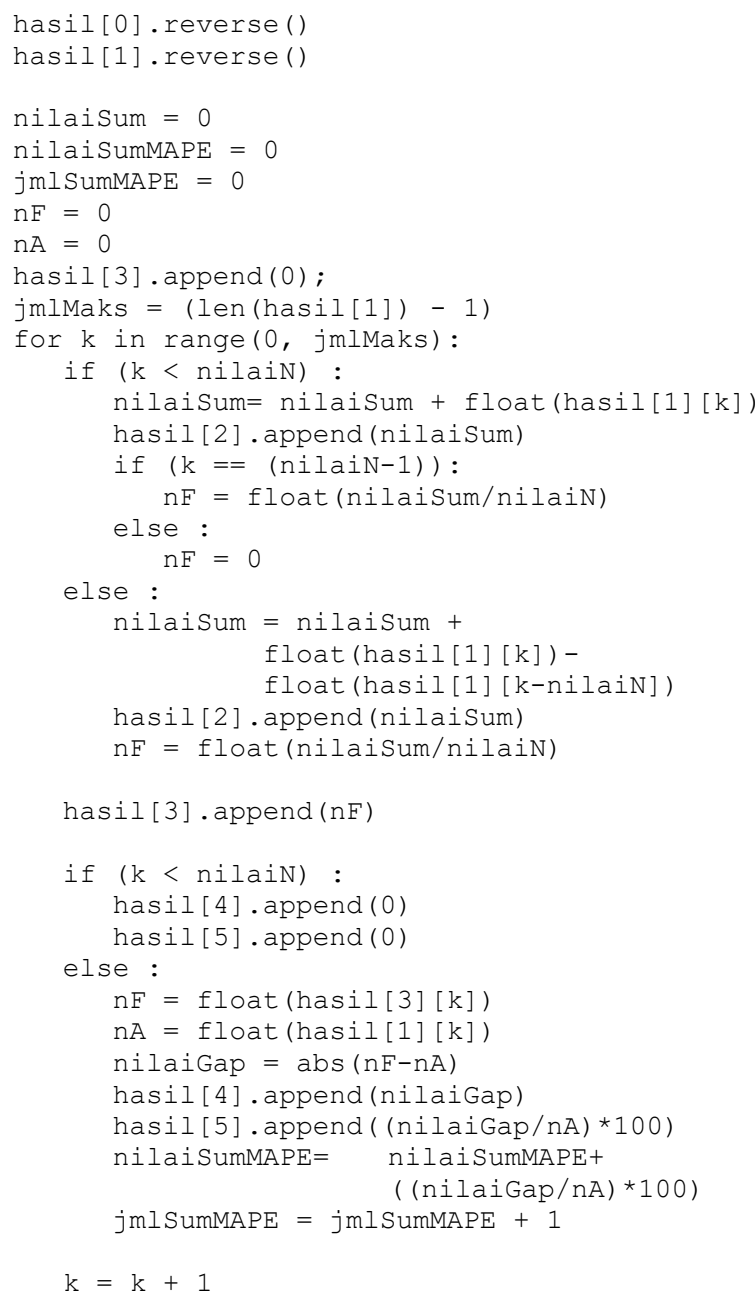

Kode di atas adalah kode program untuk menghitung nilai forecasting dan tingkat error (MAPE) nya, sekaligus menghitung pula ratarata tingkat error. Selanjutnya, hasil akhir forecasting dan tingkat akurasi ditampilkan ke layar dengan kode program sebagai berikut :

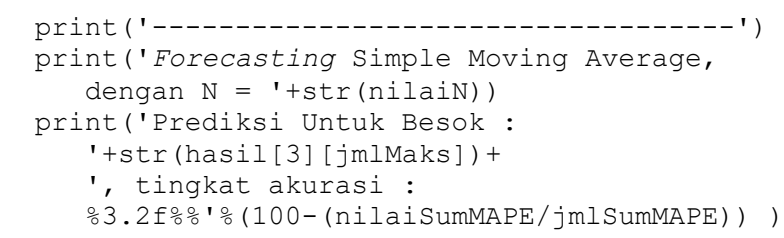

Tampilan program ketika dijalankan dapat dilihat pada gambar 3 dan tampilan hasil forecasting dapat dilihat pada gambar 4 .

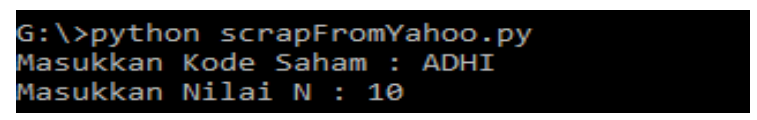

Gambar 3. Tampilan Program Forecasting

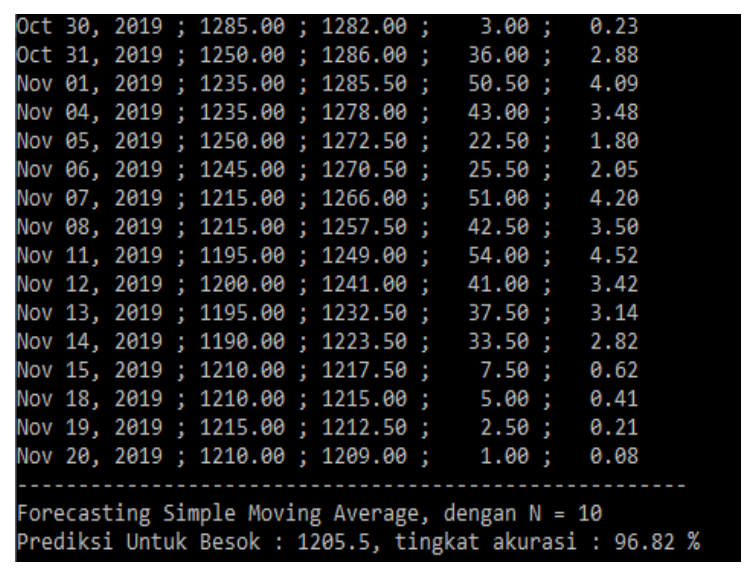

Gambar 4. Tampilan Program Ketika

\section{Menampilkan Hasil Forecasting}

\subsection{Uji Coba Program}

Pengujian program dilakukan dengan menghitung forecasting untuk keseluruhan perusahaan yang tergabung dalam LQ45 sesuai dengan daftar perusahaan di Tabel 1 . Nilai $\mathrm{N}$ dibuat berbeda-beda yaitu : $\mathrm{N}=5, \mathrm{~N}=10, \mathrm{~N}=$ $15, \mathrm{~N}=20, \mathrm{~N}=25$, dan $\mathrm{N}=30$.

Contoh hasil pengujian adalah sebagai berikut :

Tabel 2. Nilai Forecasting dengan

Nilai N yang Berbeda

\begin{tabular}{lcccccc}
\hline Kode & \multicolumn{7}{c}{ Nilai Forecasting } \\
\cline { 2 - 7 } Saham & $\mathrm{N}=5$ & 10 & 15 & 20 & 25 & 30 \\
\hline ADHI & 1207 & 1205 & 1218 & 1235 & 1245 & 1240 \\
ADRO & 1326 & 1366 & 1346 & 1348 & 1346 & 1336 \\
AKRA & 3594 & 3673 & 3742 & 3798 & 3848 & 3914 \\
ANTM & 821 & 821 & 828 & 846 & 867 & 883 \\
ASII & 6620 & 6634 & 6676 & 6736 & 6747 & 6707 \\
ASRI & 248 & 253 & 257 & 259 & 264 & 268 \\
BBCA & 31415 & 31462 & 31443 & 31468 & 31413 & 31355 \\
BBNI & 7505 & 7535 & 7521 & 7547 & 7588 & 7577 \\
BBRI & 4142 & 4155 & 4096 & 4112 & 4135 & 4143 \\
BBTN & 2102 & 2056 & 1992 & 1956 & 1959 & 1952 \\
\hline \multicolumn{6}{c}{ Catatan $:$ Data diambil pada 25 November 2019 }
\end{tabular}

Catatan : Data diambil pada 25 November 2019 
Berdasarkan hasil uji yang dilakukan terlihat bahwa program dapat berjalan dengan baik untuk menghitung semua saham LQ45.

\subsection{Analisa Keakuratan Hasil Forecasting}

Keakuratan hasil forecasting bisa diukur dengan menggunakan metode MAPE (Mean Absolute Percent Error). Tabel 3 dibawah ini menunjukkan nilai akurasi foreacasting menggunakan metode MAPE.

Perhitungan akurasi dilakukan dengan nilai $\mathrm{N}$ yang berbeda-beda pula sehingga dapat diketahui nilai $\mathrm{N}$ mana yang paling akurat.

Tabel 3. Tingkat Akurasi Forecasting

Menggunakan Metode MAPE

\begin{tabular}{|c|c|c|c|c|c|c|c|}
\hline \multirow[t]{2}{*}{ No } & \multirow{2}{*}{$\begin{array}{c}\text { Kode } \\
\text { Saham }\end{array}$} & \multicolumn{6}{|c|}{ MAPE (dalam \%) } \\
\hline & & $\mathrm{N}=5$ & 10 & 15 & 20 & 25 & 30 \\
\hline 1 & ADHI & 97,8 & 96,8 & 96,4 & 96,3 & 96,2 & 95,9 \\
\hline 2 & ADRO & 96,7 & 94,9 & 93,5 & 93,3 & 93,6 & 94,4 \\
\hline 3 & AKRA & 97,5 & 96,2 & 95,3 & 95,0 & 94,9 & 94,9 \\
\hline 4 & ANTM & 96,8 & 95,7 & 94,9 & 93,9 & 93,1 & 92,3 \\
\hline 5 & ASII & 98,4 & 97,8 & 97,2 & 96,9 & 97,0 & 97,4 \\
\hline 6 & ASRI & 98,3 & 97,3 & 96,6 & 96,3 & 95,8 & 95,1 \\
\hline 7 & BBCA & 99,3 & 99,3 & 99,0 & 98,9 & 98,8 & 98,7 \\
\hline 8 & $\mathrm{BBNI}$ & 97,8 & 96,9 & 96,1 & 95,9 & 95,8 & 95,7 \\
\hline 9 & BBRI & 98,2 & 97,7 & 97,2 & 97,1 & 97,1 & 97,2 \\
\hline 10 & BBTN & 97,0 & 95,6 & 94,5 & 94,1 & 93,8 & 93,3 \\
\hline 11 & BKSL & 97,0 & 95,9 & 95,0 & 94,6 & 94,0 & 93,6 \\
\hline 12 & BMRI & 98,2 & 97,8 & 97,2 & 96,9 & 96,6 & 96,3 \\
\hline 13 & BSDE & 97,9 & 97,5 & 97,3 & 97,6 & 97,6 & 97,7 \\
\hline 14 & CPIN & 96,3 & 95,5 & 94,3 & 93,3 & 92,4 & 91,7 \\
\hline 15 & ELSA & 98,2 & 97,7 & 97,3 & 97,1 & 97,0 & 97,0 \\
\hline 16 & EXCL & 97,9 & 97,9 & 98,0 & 97,9 & 97,9 & 97,7 \\
\hline 17 & GGRM & 96,7 & 95,6 & 94,2 & 92,9 & 91,7 & 89,8 \\
\hline 18 & HMSP & 97,0 & 96,3 & 95,5 & 94,3 & 93,1 & 91,3 \\
\hline 19 & ICBP & 98,6 & 98,2 & 97,8 & 97,5 & 97,2 & 97,1 \\
\hline 20 & INCO & 96,5 & 95,6 & 95,3 & 94,8 & 94,6 & 94,6 \\
\hline 21 & INDF & 98,6 & 98,2 & 97,7 & 97,3 & 97,3 & 97,3 \\
\hline 22 & INDY & 97,5 & 96,2 & 95,4 & 94,9 & 94,9 & 95,4 \\
\hline 23 & INKP & 96,3 & 94,8 & 93,9 & 93,7 & 93,4 & 92,7 \\
\hline 24 & INTP & 97,8 & 97,2 & 96,6 & 96,1 & 95,6 & 95,4 \\
\hline 25 & ITMG & 96,5 & 94,9 & 93,4 & 92,4 & 92,8 & 93,8 \\
\hline 26 & JSMR & 97,9 & 97,5 & 97,0 & 96,7 & 96,4 & 96,1 \\
\hline 27 & KLBF & 98,6 & 98,1 & 94,4 & 96,9 & 96,2 & 95,7 \\
\hline 28 & LPKR & 98,0 & 97,1 & 96,3 & 96,0 & 95,5 & 95,0 \\
\hline 29 & LPPF & 96,7 & 95,2 & 94,2 & 93,0 & 92,0 & 91,3 \\
\hline 30 & MEDC & 97,7 & 96,7 & 96,2 & 95,7 & 95,3 & 94,7 \\
\hline 31 & $\mathrm{MNCN}$ & 97,9 & 97,3 & 96,7 & 96,7 & 96,5 & 96,3 \\
\hline 32 & PGAS & 97,1 & 96,0 & 95,2 & 94,8 & 94,4 & 94,1 \\
\hline 33 & PTBA & 97,3 & 96,3 & 954 & 94,6 & 94,3 & 94,4 \\
\hline 34 & РТPP & 96,9 & 95,7 & 94,7 & 94,5 & 94,3 & 93,9 \\
\hline 35 & SCMA & 96,5 & 95,3 & 94,4 & 94,0 & 93,8 & 94,2 \\
\hline 36 & SMGR & 97,9 & 97,3 & 96,6 & 96,0 & 95,7 & 95,4 \\
\hline
\end{tabular}

\begin{tabular}{clcccccc}
37 & SRIL & 98,2 & 97,3 & 96,6 & 96,0 & 95,1 & 94,1 \\
38 & SSMS & 98,0 & 97,3 & 97,1 & 96,6 & 96,2 & 96,0 \\
39 & TLKM & 98,7 & 98,4 & 98,1 & 98,0 & 98,0 & 97,9 \\
40 & TPIA & 96,6 & 95,2 & 93,8 & 92,7 & 92,3 & 92,6 \\
41 & UNTR & 97,2 & 95,7 & 94,5 & 93,8 & 93,7 & 94,5 \\
42 & UNVR & 98,7 & 98,4 & 98,1 & 97,8 & 97,3 & 96,7 \\
43 & WIKA & 97,3 & 96,4 & 95,7 & 95,3 & 94,8 & 94,0 \\
44 & WSBP & 98,0 & 97,0 & 96,5 & 96,3 & 96,1 & 96,0 \\
45 & WSKT & 97,2 & 96,1 & 94,9 & 94,5 & 94,1 & 93,6 \\
Rata-rata & 97,6 & 96,7 & 95,9 & 95,5 & 95,2 & 95,0 \\
\hline \multicolumn{6}{c}{ Catatan : Data diambil pada 25 November 2019 }
\end{tabular}

\section{KESIMPULAN}

Pada penelitian ini, web scrapping dengan menggunakan Python dan library BeautifullSoup berjalan dengan baik. Tingkat akurasi perhitungan forecasting Simple Moving Average dengan menggunakan Metode MAPE (Mean Absolute Percent Error) pada saham LQ45 menunjukkan bahwa perhitungan dengan nilai $\mathrm{N}$ $=5$ memberikan tingkat akurasi yang paling tinggi yaitu 97,6\%. Sedangkan tingkat akurasi yang paling rendah adalah menggunakan nilai $\mathrm{N}$ = 30 yaitu 95,0 \% . Hasil ini juga menunjukkan bahwa semakin kecil nilai $\mathrm{N}$, maka tingkat akurasi menjadi lebih baik.

\section{DAFTAR PUSTAKA}

[1] Departemen Pendidikan Nasional, Kamus Besar Bahasa Indonesia. Pusat Bahasa Edisi Ketiga, Jakarta: PT. Gramedia Pustaka Utama, 2005.

[2] Bursa Efek Indonesia, "Saham", [Online]. Available:https://www.idx.co.id/produk/sah am/. [Accessed: 25-Nov-2019].

[3] Sutrisno. Manajemen Keuangan Teori, Konsep dan Aplikasi. Yogyakarta: EKONISIA, 2012.

[4] Cahyono, Jaka. E, Strategi dan eknik Meraih Untung di Bursa Saham. Jakarta : Elex Media Komputindo, 2001.

[5] Sulistiawan, Dedhy, Liliana, Analisis Teknikal Modern pada Perdagangan 
Sekuritas. Yogyakarta : Penerbit Andi, 2007.

[6] Nurlifa, Alfian, Kusumadewi, Sri, Sistem Peramalan Jumlah Penjualan Menggunakan Metode Moving Average Pada Rumah Jilbab Zaky. Jurnal Inovtek Polbeng - Seri Informatika, Vol 2, No 1, 2017.

[7] Sundari, Shinta Siti, Susanto, Revianti, Wivia, Sistem Peramalan Persediaan Barang Dengan Weight Moving Average Di Toko The Kids 24. Konferensi Nasional Sistem \& Informatika, 2015.

[8] Sanders, Nada, Forecasting Fundamentals. New York: Business Expert Press, 2016.

[9] Turland, Matthew, Phparchitect's Guide to Web Scraping with PHP. Alexandria: musketeers.me, 2010.

[10] Josi, A., Abdillah, L.A., \& Suryayusra, Penerapan teknik web scraping pada mesin pencari artikel ilmiah. ArXiv, abs/1410.5777, 2014. 